\title{
VAMEE: A Value Aware Method for Evaluating Inclusive E-Government Initiatives
}

\author{
Gustaf Juell-Skielse and Erik Perjons \\ Department of Computer and Systems Sciences, Stockholm University \\ $\{\mathrm{gj}$ s, perjons\}@dsv.su.se
}

\begin{abstract}
The growing use of ICT solutions for improving the public sector has created a need for valuating e-government initiatives. A number of methods for this purpose have been developed, but they are typically restricted to analyzing the benefits and costs of only one single actor. There is, therefore, a need for methods that take a broader view and take into account entire networks of actors. This paper proposes a novel method, called VAMEE, the purpose of which is to produce a well-grounded and easily understandable valuation of an e-government initiative that takes into consideration the benefits, costs, and interrelationships of all actors concerned. The basis of the proposed method is a combination of enterprise modeling techniques, in particular goal modeling and value modeling, with an established method for cost benefit analysis (i.e. Peng). VAMEE is designed to be inclusive, easily understandable, and visual. These properties of the method will support accurate and unbiased valuations as well as improved innovation in the development of e-government initiatives.
\end{abstract}

Keywords: e-government, benefit analysis, enterprise modeling, goal modeling, value modeling, requirements engineering.

\section{Introduction}

The growing interest in applying ICT to achieve better government [1] emphasizes the need for benefits valuation methods for e-government initiatives. E-government initiatives include investments in e-services to improve citizen service [2] as well as integrated processes to enhance government back office operations [3]. Through privatization and public private partnerships [4], e-government initiatives involve and affect entire networks of actors that depend on each other in terms of value creation, including actors such as citizens, employees at different levels of government, third party service providers, and companies [5]. Often, the benefits and costs of egovernment initiatives are unevenly distributed among the actors, and one actor could carry a large portion of the costs while most of the benefits are reaped by other actors [6]. For example, local governments may carry costs for e-service platforms that primarily lead to administrative savings at third party service providers.

There are a number of models and methods available to measure and control egovernment initiatives. The Value measuring methodology [7] by the CIO Council and the Guide for benefit realization [8] by the e-Government Delegation are two 
examples of methods developed for measuring e-government initiatives. These methods include definitions of key concepts and steps to follow in order to measure costs and benefits of investments in e-government. However, they do not take into account the multitude of actors involved and their interdependence in terms of value creation. Hence, the methods take an internal rather than an external perspective on egovernment and focus on the benefits and costs of only one single actor. This restricted perspective limits the understanding of how investments in e-government enables value creation among networks of actors, which in turn may lead to erroneous investment decisions and slow e-government development and uptake.

The complexity of e-government initiatives has created a need for a practical approach that takes into account all actors involved in value creation, visualizes their relationships, and estimates the total value of such initiatives. In two previous papers $[6,9]$, we have presented and demonstrated such an approach for benefits valuation of e-government initiatives. The approach combines two established approaches, Peng [10] and value modeling [11], to visualize both the actors involved and the value creation that takes place within and between these actors.

In this paper, the purpose is to convert and extend the combined approach into a thorough and easily applicable method by clarifying and detailing its design objectives as well as its phases and activities. In addition, we expand the scope to include key aspects of change management, such as actor involvement and goal modeling. The method is named A Value Aware Method for Evaluating Inclusive EGovernment Initiatives (VAMEE). The goal of VAMEE is to produce a wellgrounded and easily understandable valuation of an e-government initiative that takes into consideration the benefits, costs, and interrelationships of all actors concerned. The basis of VAMEE is a combination of enterprise modeling techniques, in particular goal modeling and value modeling, with an established method for cost benefit analysis, i.e. the Peng method [10].

The paper is structured as follows. Section 2 gives the theoretical bases of the proposed method and describes the fundamentals of goal modeling, value modeling, and the Peng method for cost benefit analysis. Section 3 discusses the design science approach used for developing VAMEE, and introduces a running example based on a case study. Section 4 describes VAMEE in detail, and Section 5 provides a brief demonstration and evaluation of the method. Section 6 compares VAMEE to other valuation approaches in the literature, and Section 7 concludes the paper and suggests directions for future work.

\section{Theoretical Bases for VAMEE}

The VAMEE method is based on three types of modeling approaches: cost benefit analysis using Peng, value modeling, and goal modeling.

\subsection{Cost Benefit Analysis Using Peng}

Peng has become a popular method for cost and benefits evaluation of IT-investments and process changes, in both the private and the public sector [10,12]. It is presented 
as a "structural method to evaluate, in dollars, all the different types of benefits that IT generates within an operation" [10, p.26]. It is similar to the Value Measurement Model [7] and includes both soft and hard measures [2]. The method consists of ten steps, and ideally it involves users and managers as well as functional and technical specialists from an organization. In Peng, cost and benefits are identified in workshops and organized in tree structures that depict the relationships between benefits, costs, process changes and IT functionality. All cost and benefits are expressed in monetary terms, although the intention is not to achieve accounting precision. In order to validate the results, the benefits are classified as direct, indirect and intangible benefits. Identification of IT costs is supported by a predefined list of types of costs. In the final step, the net value of the benefits and costs are calculated, and managers responsible for the realization of the benefits are appointed.

In addition, the many books on Peng provide a large number of cases from a variety of industries where the method has been applied. Through case based reasoning [13], participants can solve their own case by using or adapting existing cases. In a study of the Peng method [14], its strengths were found to be the business process oriented approach, the mixture of personnel categories participating in the evaluation, as well as the inclusion of assessing soft benefits. Weaknesses were found to be the difficulties of attracting and involving the right participants, the subjective nature of assessment, and difficulties in verifying the net values.

The main terms from the Peng method, benefit and cost, are in this paper defined as:

A benefit is an increase in a resource, expressed in monetary terms, that is caused by the implementation of an e-government initiative.

A cost is a decrease in a resource, expressed in monetary terms, that is caused by the implementation of an e-government initiative.

\subsection{Value Modeling}

A value model is a representation of a network of cooperating actors that together create value through resource transfers. A value model aims to provide a high level view of a value network using a limited set of modeling elements, such as actor, resource, and resource transfer. Value modeling can be a basis for profitability analysis, that is, reasoning about the economic viability of the actors participating in a value network; for process and service design, that is, as a foundation for designing business processes and services for involved actors in the network; and for relationship analysis, that is, establishing roles and responsibilities among different actors in the network.

There exists a number of value modeling techniques and ontologies, such as REA [15], BMO [16] and e3value [11]. The value modeling technique used in this paper is in line with the e3value technique. However, both the syntax and semantics differ in some respects in order to arrive at a technique that is as simple as possible given its purpose.

The main modeling elements in the value modeling technique used in this paper are: actor, resource, and resource transfer, which are defined as follows: 
An actor is a human being, role, organization or organizational unit that can participate in the transfer of resources. Actor can refer to an individual actor (e.g. "Child Care Administration"), or a role (i.e. actor category, such as "Parent" and "Day Care Unit") that can be taken by multiple individual actors. In the notation, the actor is represented as a rectangle with a stick figure and the actor's name, see Figure 1.

An economic resource is an object that is viewed as being valuable by some actor and such that an actor can have legal control over it and transfers it to other actors. A resource can be categorized into one of the following categories: a good (e.g. "Food"); a service (e.g. "Day Care Service"); information (e.g. "Child Care Usage Info"); and money (e.g. "Child Care Fee"). In the notation, an economic resource is represented as a label on the transfer symbol (i.e. an arrow), and the category of the economic resource is represented as a label between square brackets after the economic resource label, see Figure 1.

A resource transfer is an action in which the right on an economic resource is handed over from one actor to another. For example, a day care service (an economic resource of the category "service") is transferred from a day nurse unit to a parent, which means that the parent has the right to use the service. In the notation, the transfer is represented as an arrow between two actors, see Figure 1.

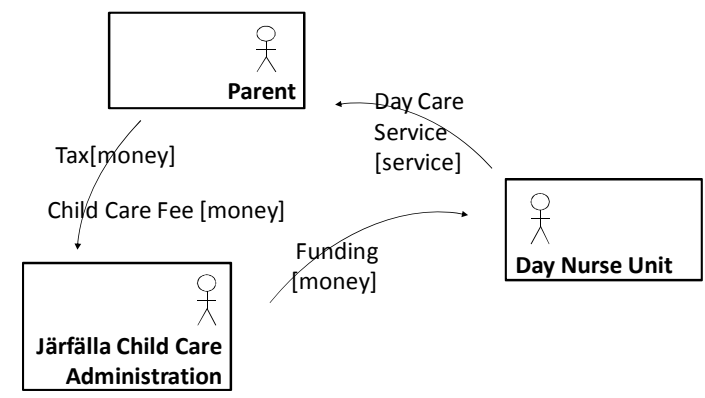

Fig. 1. A Value model of a child care network in a Swedish municipality. The Value model is on operational level.

Value models could be constructed on different levels. In this paper we use two different levels: operational and policy/planning, see Figure 2.
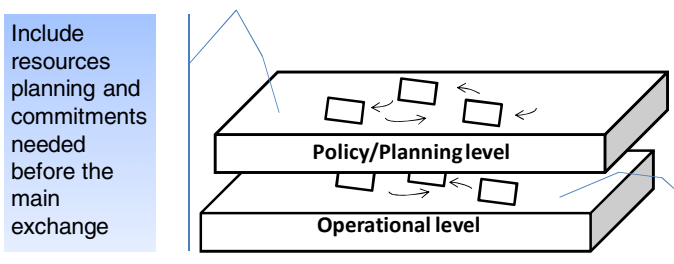

Fig. 2. Value models on different levels
Main exchanges in a network 
A value model on the operational level represents the transfers of economic resources on the operational level, such as in Figure 1. Resource transfers on the operational level are the main transfers of economic resources between actors in a value network.

A value model on the policy/planning level includes resource transfers that support planning (e.g. scheduling) and commitments (e.g. orders), see Figure 2. These policy/planning level economic resource transfers are needed in some business settings before the transfers of economic resources on the operational level can be carried out. Another way to put it is that the results of economic resource transfers on the policy/planning level are used to regulate the economic resource transfers on the operational level.

\subsection{Goal Modeling}

A goal model is a representation of enterprise goals, usually structured as a hierarchy in which high levels goals are decomposed into sub-goals (which are supported by means). Goal modeling can be used to identify and structure desirable states of an actor in order to drive the actor towards these states.

There exists a number of goal modeling techniques and ontologies, such as $i^{*}$ [17] and the Business Motivation Model (BMM) [18]. The goal modeling technique used in this paper is in line with the BMM technique. However, both the syntax and semantics differ in some respects in order to arrive at a technique that is as simple as possible given its purpose.

The main modeling elements in the goal modeling technique presented in this paper are goals and relations between these.

A goal is a statement about a desirable state of an actor. A goal can be decomposed into several sub-goals.

\subsection{Motivating the Theoretical Bases}

The VAMEE method is based on three types of modeling approaches: cost benefit analysis using Peng, value modeling, and goal modeling. Peng is a participative, bottom-up approach for identifying and valuating of IT-enabled benefits and costs [10]. However, Peng focus on the benefits and costs of one single actor and does not take into account the multitude of actors involved in e-government initiative. Value modeling is a well established top-down approach for visualizing the complete network of actors involved in the value creation process. A value model provides a high level view of the resources that are exchanged among the actors of a network. Therefore, value modeling can extend the one actor's perspective of Peng by taking a network perspective. Goal modeling helps in identifying and formulating desirable future states of an actor, and supports the Peng method's identification of benefit and cost of e-government initiative. All three approaches aid in the understanding of how IT, process changes and economic value are interrelated and how an e-government initiative affects actors involved in a value network. 


\section{Methodological and Empirical Bases for VAMEE}

This section describes the research strategy used, the objectives of VAMEE, and the case study in which the method was designed and applied. The case study is also the basis for the running example used in Section 4.

\subsection{Design Science}

For developing the method, we have used design science [19, 20] as a research strategy, in particular Peffers et al.'s model for design research [20], which consists of six steps:

1. Identify problem and motivate

2. Define objectives of a solution

3. Design and develop

4. Demonstration

5. Evaluation

6. Communication

The problem and its motivation have been discussed in Section 1. In the following sections, the remaining steps are addressed.

\subsection{Objectives of the Method}

The overall objective is to provide a method for measuring and controlling egovernment initiatives, which is applicable to networks of actors and can be easily adopted in practice. This overall objective is broken down into three specific objectives for the method:

- Inclusive in terms of involving all actors of a network

- Comprehensible for actors in the public sector

- Complementary to commonly used project management and system development methods

\subsection{Case Study}

VAMEE has been designed during an e-government initiative study in the area of child care in Järfälla, a Swedish municipality $[6,9]$. The method has been applied and the result has been used for refining the method.

The municipality Järfälla is one of Sweden's 290 municipalities, located 20 kilometers Northwest of Stockholm. With 65000 inhabitants, it is, by Swedish standards, a relatively large municipality. More than 3000 children in the age of 1-5 years are engaged in the child care provided by the municipality. Approximately three fourths of the day nurse units are owned by the municipality, and one fourth is privately owned. 
The interaction between parents and child care administration is made up of four processes:

- Application and placement offer

- Schedule changes

- Salary changes

- Termination of contract

The interaction between parents and child care administration are based on paper forms that are sent using traditional mail services. A lot of phone contacts are made between parents and child care administrators, especially during the process of application and placement.

Schedule changes, which is the basis of the e-government initiative used as a running example in this paper, are primarily driven by changes in parents work schedules and are handled through forms that are handed in manually at the day nurse units. In 2007, Järfälla introduced e-services in order to replace the manual forms and the physical handling of these forms.

\section{Description of VAMEE}

This section describes VAMEE, which consists of two phases: Motivate and Investigate, see Figure 3. Motivate consist of three activities and Investigate of two activities.

\begin{tabular}{|c|c|c|}
\hline Phases & Activities & Output \\
\hline $\begin{array}{l}1 . \\
\text { Motivate }\end{array}$ & 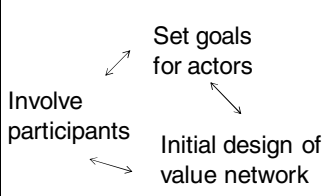 & $\begin{array}{l}\text { - Formulated } \\
\text { goals } \\
\text { - Communicated } \\
\text { commitment } \\
\text { - Visualized } \\
\text { value network }\end{array}$ \\
\hline $\begin{array}{l}2 . \\
\text { Investigate }\end{array}$ & $\begin{array}{l}\text { Analyze benefits } \\
\text { and cost } \\
\qquad \begin{array}{l}\text { Syntezise } \\
\text { value } \\
\text { network }\end{array}\end{array}$ & $\begin{array}{l}\text {-Calculated net } \\
\text { value } \\
\text { - Syntesized } \\
\text { and visuallized } \\
\text { value network }\end{array}$ \\
\hline
\end{tabular}

Fig. 3. The phases and activities of the VAMEE Method

\subsection{Overall Design of the Method}

VAMEE was constructed using Peng as a starting point. It has inherited much of the characteristics of Peng: user participation, bottom-up determination of costs and benefits, and a methodical approach. VAMEE has also inherited the characteristics of 
value modeling: a top-down approach for visualizing the entire network of actors involved in the value creation process as well as a value modeling ontology [11]. In addition, VAMEE emphasizes iteration, both within and between phases. For example, goals and value network descriptions are refined in several iterations, moving from ideas to detailed descriptions and commitments. Through iteration, the dynamic nature and learning aspects of technological change is recognized.

\subsection{The Motivate Phase}

The phase Motivate aims at establishing a preliminary understanding of the goal and scope of the e-government initiative under consideration and to mobilize participants for the work in the following phases. The phase includes the following activities: Set Goals for Actors, Involve Participants, and Initial Design of Value Network.

\section{Set Goals for Actors}

The activity Set Goals for Actors aims at formulating goals for the e-government initiative, e.g. to improve the quality of citizen service and to become more cost effective. There exists a multitude of independent actors in the public sector and it is important to clarify goals for each actor. Typically, this activity would start with discussions within one actor or in discussions between a small numbers of actors. In iterations between this activity and the activities Initial Design of Value Network and Involve Participants, actors affected by the e-government initiative are successively identified and subsequently involved in goal discussions. The activity is completed when all actors affected by the e-government initiative have formulated and agreed on individual goals and their relations. Conflicts between the goals need to be managed in this activity, or in the second phase and the Synthesize activity. The output of this activity is goal statements for each actor.

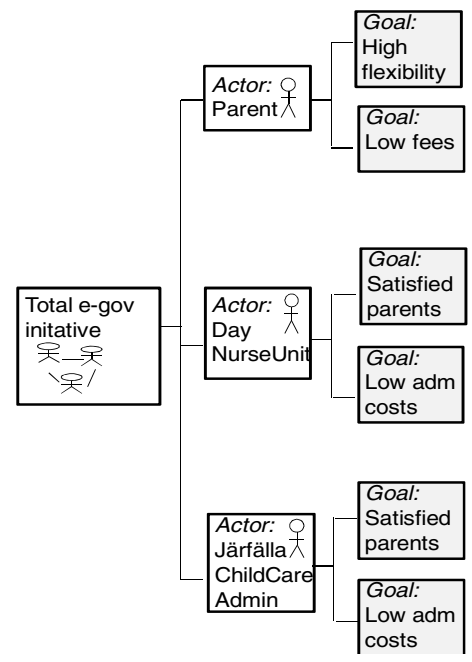

Fig. 4. The goals for the actors involved in the e-government initiative 
Running example: In the case at Järfälla municipality, three actors were identified: the Child Care Administration at the municipality, a private Day Nurse Unit, and the parents. The main goals, in the context of the e-government initiative, for the Child Care Administration and the Day Nurse Unit were Low costs for administrative work and Satisfied parents, while the main goals for the parents were High flexibility and Low fees, see Figure 4. These goals were elicited in discussions with participants representing the three actors.

\section{Involve Participants}

The activity Involve Participants aims at involving participants representing all actors in the value network. Ideally, both managers and functional experts from each actor are involved, thereby ensuring that decision powers, as well as operational understanding, are available. In this activity, the participants approve of the preliminary goals and they develop a shared understanding of how VAMEE will be applied. As the value network is scoped, the number of actors may increase, and more participants need to be involved in the work. The activity is completed when participants from all actors have taken an active part in the initial cost benefit analysis; have committed to preliminary goals; and have arrived at an adequate understanding of how VAMEE will be applied.

Running example: In the Järfälla case, relevant participants for the Child Care Administration included both managers and public servants, while the Day Nurse Unit included managers as well as child-care staff, see Figure 5.

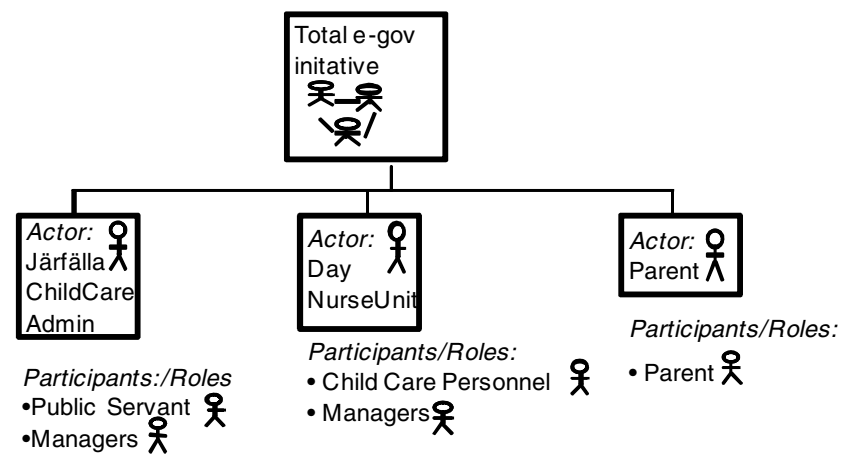

Fig. 5. The actors and participants/roles in the e-governmental initiative

\section{Initial Design of Value Network}

The activity Initial Design of Value Network aims at specifying actors as well as resource transfers in the value network for the e-government initiative. This can be a highly complicated task when analyzing the public sector. First, there are many different governmental organizations at local, regional and national levels that regularly collaborate to provide governmental services to the citizens. Second, in most 
governmental areas, there are public organizations that source or purchase the services, using tax revenue from citizens. Third, there are organizations that will provide the services. In many countries, the latter type of organizations can be publicly or privately owned, but funded by public organizations.

The result of this activity will be a visualized draft of a value network for the egovernment initiative, which will be refined in the next phase.

Running example: The value network for the Järfälla case when introducing a schedule change service is shown in Figure 6. The diagram identifies the three actors of the case as well as the main resource transfers between them. As can be seen, these resources are various kinds of information in digital form as well as an e-service. For example, the parents will provide the Day Nurse Unit with information on their planned child care usage in digital form, and the Child Care Administration will provide parents with the e-service for changing the schedule.

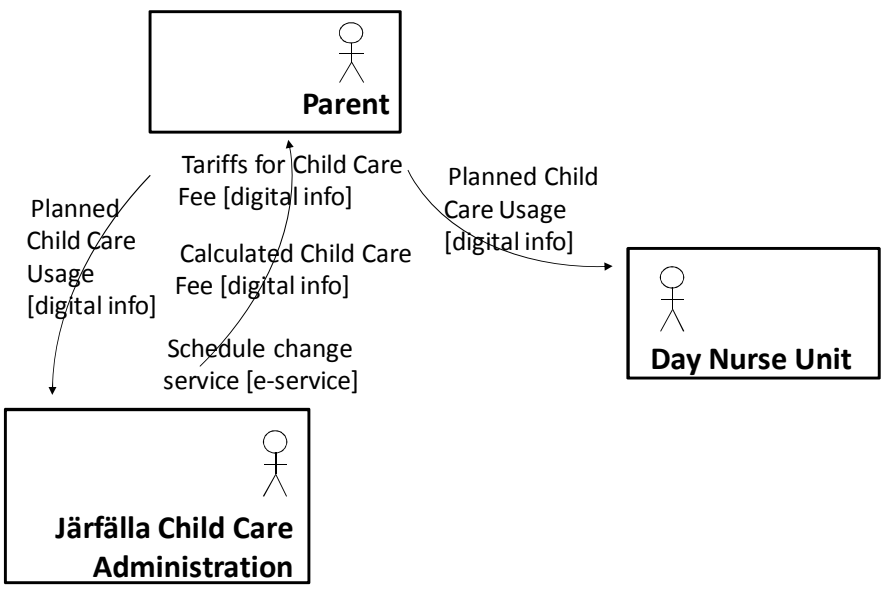

Fig. 6. A Value model on policy level of a child care network

\subsection{The Investigate Phase}

The phase Investigate aims at identifying and quantifying costs and benefits for each of the actors involved in the e-government initiative. Investigate is made up of the activities Analyze Benefits and Costs and Synthesize Value Network.

\section{Analyze Benefits and Costs}

The activity Analyze Benefits and Costs aims at identifying and estimating costs and benefits for each of the actors in the value network. Benefits and costs are identified in workshops and organized in a tree structure that depicts the relationships between benefits, process changes, and IT functionality. Identification of IT costs is supported by a predefined list of cost types. All benefits and costs are expressed in monetary terms although the intention is not to achieve accounting precision. The net value of the benefits and costs are calculated. 


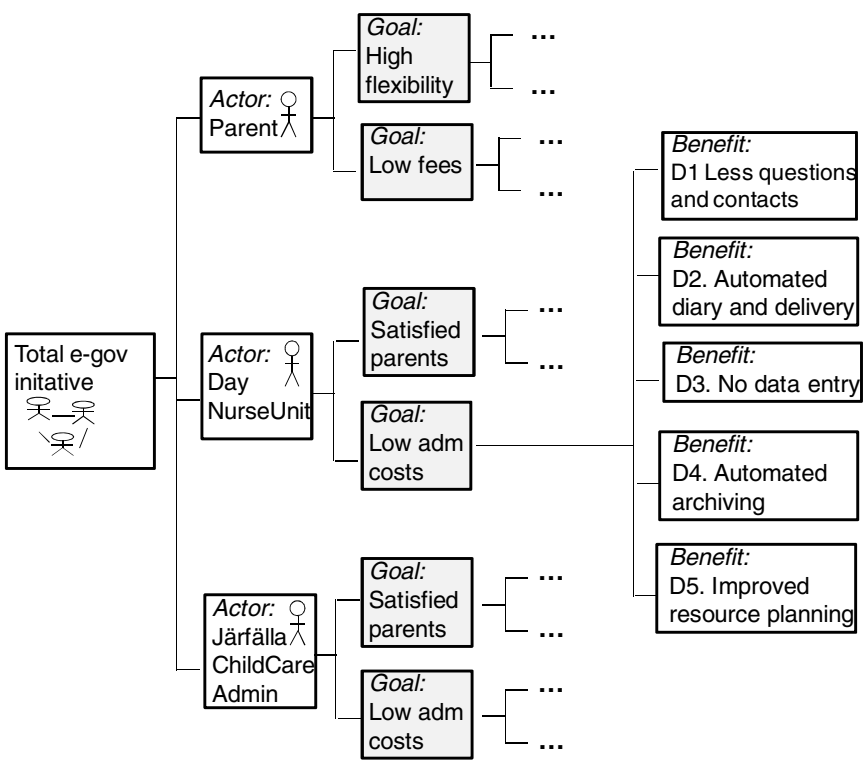

Fig. 7. The benefits related to the goal "Low adm costs" of the Day Nurse Unit

Running example: The benefits describe and quantify in monetary terms what improvements can be achieved if the e-government initiative is implemented, including both e-services and administrative back-office systems. For reasons of space, we only show the benefits of the Day Nurse Unit, see Figure 7. The costs as well as the relations between the costs, benefits, business processes and IT are showned in [9]. The benefits for the goal "Low Adminstrative Costs" for Day Nurse Unit are:

D1. Less questions and contacts (saving $39000 \mathrm{SEK} / \mathrm{year}$ ). The form used by the e-service includes information and controls that reduce the need for direct contact with the day nurseries.

D2. Automated diary and delivery (saving 39000 SEK/year). Manual diary entry is replaced by automated handling by a workflow system.

D3. No data entry (saving 104000 SEK/year). There is no longer need for manual data entry at the day nurse units since data is already entered by parents using the e-service.

D4. Automated archiving (saving 26000 SEK/year). Archiving is automated in the workflow system and replaces physical archives.

D5. Improved resource planning (N/A). Schedules provided by parents are used for resource planning at day nurse units. The day nursery staffing plans become more accurate when the quality of the information provided by the parents improves. However, the value of this item was not assessed in the cost benefits analysis. 


\section{Synthesize Value Network}

The activity Synthesize Value Network aims at mapping the results from the activity Analyze Benefits and Costs to the value model. In this activity, the benefits and costs from the Peng analysis will be mapped to the transfers of economic resources visualized in the value model, created in the previous phase. The benefits and costs are shown within parentheses after the resource labels. If a benefit or cost cannot be mapped to a resource transfer, another resource transfer needs to be added to the value model. The final step is to analyze the distribution of values visualized in the value model (i.e. actors and their transfers of economic resources) together with the results from the benefit and cost analysis in the previous activity. This will support government officials to prioritize e-government initiatives.

Running example: The initial value model from Figure 6 is in Figure 8 extended by mapping its resource transfers to benefits (for example benefits D1 to D5 presented in the previous step). That is, the model in Figure 8 shows which resource transfers that contribute to the various benefits. (Costs are not shown in Figure 8.)

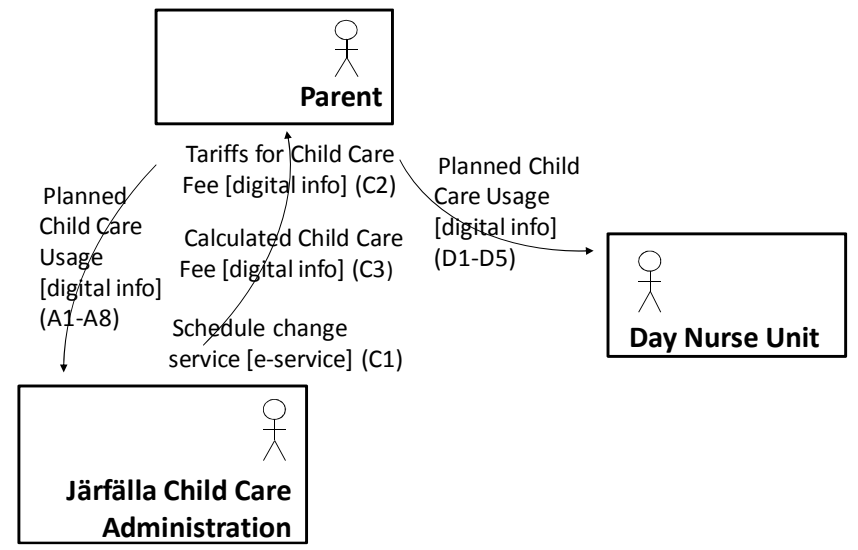

Fig. 8. A Value model on policy level of a child care network in the e-government initiative, including the benefits

\section{Demonstration and Evaluation}

Most parts of the method have been used in a case at Järfälla municipality, as described in Section 3. The experiences from this use provide an initial demonstration of the method and indicate that the method supports users in identifying actors and benefits that were not included at the beginning of the Järfälla municipality egovernment initiative, [9]. The method has not yet been empirically evaluated in a thorough way, but we here offer an evaluation in the form of informed arguments:

- Inclusive in terms of involving all actors of a network: The visualization of the value network supports the identification of all relevant actors in an e-government initiative. Furthermore, as all actors are visualized in the network, it becomes 
easier for them to understand their role and contribute to the development and evaluation of the initiative. There is also a specific activity in VAMEE, Involve participants, that supports this objective.

- Comprehensible for actors in the public sector: VAMEE is based on well-known concepts such as actor, goal, resource, benefit and cost, which are all widely used in the public sector. Furthermore, the method's results are offered in a visual form.

- Complementary to commonly used project management and systems development methods: The method includes a value network perspective which is usually not considered in project management and systems development methods, thereby providing a complementary perspective to such methods. Furthermore, the method can easily be included, as a plug-in, in any project management or systems development method, as the goals in the VAMEE method can work as an interface to the goals specified in other kinds of methods.

\section{Related Research}

The increased investments in e-government in recent years have led to an increased interest in evaluating the results of e-government investments. Therefore, many researchers and practitioners have presented and discussed methods for evaluation, but also which types of benefits and costs shall be used for measuring investments in the public sector.

In this paper, value modeling, goal modeling and benefit analysis based on Peng are combined in order to produce an evaluation of an e-government initiative.

Value models have been used for profitability analysis [11, 21]. Such an analysis addresses the volumes and monetary values of resource exchanges in a value network. The aim is to analyze the economic viability of the network. However, existing profitability analyses using value models have no support for how to estimate the revenues and costs. The VAMEE method includes such support.

Using process analysis [22, 23] as the basis for evaluating the result of egovernment investments is a common approach in research, but these are mainly focusing on one actor and not the entire network of actors, which is the focus of the VAMEE method.

There are many research papers specifying which benefits, costs, and dimensions of benefits and costs that need to be measured in cost benefit analysis [2, 7, 24]. In general, both researchers and practitioners have stated that such benefits, costs, or dimensions need to consist of both monetary values and softer values, such as social and public values. Several multidimensional frameworks for the evaluation of egovernmental initiatives have, therefore, been designed [25]. However, several researchers have claimed that the types of benefits and cost depend on the situation for the e-government initiative and cannot be specified in advance [26]. The VAMEE method supports actors to specify benefits and cost for the e-government initiative based on the situation for the e-government initiative. 


\section{$7 \quad$ Conclusions and Future Work}

In this paper, we have proposed a new method for the valuation of e-government initiatives. The characteristics of the method include a network perspective, a high degree of visualization, and a firm grounding in enterprise modeling. Utilizing enterprise modeling for the purpose of valuation enables organizations to manage knowledge about themselves and the environment in which they are embedded. The method has been successfully used in a case at a Swedish municipality.

A main advantage of the method is that it widens the perspective of the actors involved in an e-government initiative, as the method requires the benefits, costs and interrelationships of all actors to be made explicit and taken into account. This widened perspective contributes to the correctness of the evaluation, as the interests of all concerned actors are taken into consideration. The broader perspective also supports innovation, as involving more actors opens up new opportunities for value creation and distribution. To involve all concerned actors is particularly important in the public sector, where the needs and interests of all citizens have to be respected.

Future work will focus on further widening the perspective on the benefits of an egovernment initiative. The current use of the Peng method requires the benefits to be expressed in monetary terms, i.e. benefits are viewed in one dimension only. However, a multi-dimensional view on benefits can be preferable in many circumstances and should be investigated. Furthermore, the method needs more validation through comprehensive case studies and the involvement of other relevant actors such as software vendors.

\section{References}

1. Grönlund, Å.: Ten Years of E-Government: The 'End of History' and New Beginning. In: Wimmer, M.A., Chappelet, J.-L., Janssen, M., Scholl, H.J. (eds.) EGOV 2010. LNCS, vol. 6228, pp. 13-24. Springer, Heidelberg (2010)

2. Gupta, M.P., Jana, D.: E-government evaluation: A framework and case study. Government Information Quarterly 20, 365-387 (2003)

3. European Commission, A Digital Agenda for Europe, http: / /eurlex. europa.eu/LexUriServ/ LexUriServ.do?uri=COM: 2010 : 0245 :REV1: EN (viewed May 20, 2011)

4. Savas, E.S.: Privatization and Public-Private Partnerships. CQ Press, Washington (2000)

5. Swedish Association of Local Authorities and Regions, Local self-government, http: / / www.skl.se/artikel.asp?A=48688\&C=6393 (viewed December 7, 2009)

6. Juell-Skielse, G., Perjons, E.: New Challenges for e-Government: Value Realization among Independent Actors. In: 4th International Conference on Research Challenges in Information Science (RCIS), pp. 437-445. IEEE Computer Society, Los Alamitos (2010)

7. CIO Council. The value measuring methodology: Highlights. Washington, DC7 CIO Council, Best Practices Committee (2001) 
8. E-Government Delegation. Vägledning i nyttorealisering,

http://www. edelegationen.se/sites/default/files/imce/ filer/publikationer/Vagledning_i_Nyttorealisering.pdf (viewed June 30, 2011)

9. Juell-Skielse, G., Perjons, E.: Improving E-Government through Benefit Analysis and Value Modeling. In: Ahamed, S.I., Bertino, E., Chang, C.K., Getov, V., Liu, L., Ming, H., Subramanyan, R. (eds.) Proceedings of the 33rd Annual IEEE International Computer Software and Applications Conference, COMPSAC 2009, Seattle, Washington, USA, July 20-24, pp. 332-339. IEEE Computer Society, Los Alamitos (2009)

10. Dahlgren, L.E., Lundgren, G., Stigberg, L.: Make IT profitable: PENG - A practical tool for financial evaluation of IT benefits, Ekerlids Förlag (1997)

11. Gordijn, J., Akkermans, H.: Value based requirements engineering: Exploring innovative e-commerce idea. Req. Engineering Journal 8(2), 114-134 (2003)

12. Dahlgren, L.E., Lundgren, G., Stigberg, L.: Öka nyttan av IT i vården!: att skapa och värdera nytta i verksamheten med hjälp av PENG-modellen, Ekerlids (2003) (In Swedish)

13. Riesbeck, C.K., Schank, R.: Inside Case-based Reasoning. Erlbaum, Mahwah (1989)

14. Fredriksson, O.: Beyond Assessing Economic Net Value from Electronic CommerceSupported Business Process Redesign - a Discussion of the PENG Method. In: Bubenko jr, J., Fischer-Hübner, S., Lindskog, S., Nilsson, A.G. (eds.) Proceedings of the Promote IT 2004 Conference, May 5-7, pp. 382-393. Karlstad University (2004)

15. McCarthy, W.E.: The REA Accounting Model: A Generalized Fra,ework for Accounting Systems in Shared Data Environment, The Accounting Review (1982)

16. Osterwalder, A.: The Business Model Ontology, PhD thesis, HEC Lausanne (2004), http: / / www.hec.unil.ch/aosterwa/ (accessed January 5, 2008)

17. Yu, E.: Modeling Strategic relationships for process engineering. Dep. Of Computer Science, University of Toronto (1995)

18. OMG Business Motivation Model, Version 1.1, Object Management Group (2010b), http: / / www . omg .org/spec/BMM/1.1/, maj2 010 (April 19, 2011)

19. Hevner, A.R., March, S.T., Park, J., Ram, S.: Design science in information systems research. MIS Quarterly 28(1), 75-106 (2004)

20. Peffers, K., Tuunanen, T., Rothenberger, M., Chatterjee, S.: A Design Science Research Methodology for Information Systems Research. Journal of Management Information Systems 24(3), 45-77 (2008)

21. Johannesson, P., Andersson, B., Weigand, H.: Resourse Analysis and Classification of Purpose Driven Value Model Design. Int. Journal of Information System Modeling and Design 1(1), 56-78

22. Kohli, R., Hoadley, E.: Towards Developing a Framework for Measuring Organizational Impact of IT-Enabled BPR: Case Studies of Three Firms. The Data Base for Advances in Information Systems 37(1) (2006)

23. Becker, J., Bergener, P., Räckers, M.: Process-Based Governance in Public Administration Using Activity-Based Costing. In: Wimmer, M.A., Scholl, H.J., Janssen, M., Traunmüller, R. (eds.) EGOV 2009. LNCS, vol. 5693, pp. 176-187. Springer, Heidelberg (2009)

24. Grimsley, M., Meehan, A.: e-Government information systems: Evaluation-led design for public value and client trust. European Journal of Information Systems 16, 134-148 (2007)

25. Chircu, A.M.: E-government evaluation: towards a multidimensional framework. Electronic Government 5(4), 345-363 (2008)

26. Irani, Z., Love, P., Elliman, T., Jones, S., Themistocleous, M.: Evaluating e-Government: learning from the experiences of two UK local authorities. Information Systems Journal 15, 61-82 (2005) 